\title{
Way of Life of the Educational Organization: Intellectual Model
}

\author{
Tatiana Korsakova ${ }^{1, *}$, Mikhail Korsakov ${ }^{2}$ \\ ${ }^{1}$ Associate professor, management department of SFedU \\ ${ }^{2} \mathrm{Head}$ of economic department of SFedU \\ *Corresponding author: takors@ @ail.ru
}

\author{
Received December 25, 2012; Revised May 09, 2013; Accepted May 10, 2013
}

\begin{abstract}
This problem analytical scientific article informs the reader about nowadays academic standards of secondary school management and their suitability to social, historical, political and economic realities of the development of civilization. It sets out and protects by academic evidence different points of view on the new enough concept of «Way of educational organization life», gives modern approaches to the problem and methods for its solution, justifies the concept. It is built on the rules of the logic of scientific research. The presented intellectual model of Way of life of educational organization is based on the most important elements of intellectual capital, and the latent factors of cumulative approach to the development of the educational organization. As the way of life of the educational institutions is multifaceted and complex phenomenon of reality six main factors of the intellectual model were appointed in the paper. As the way of life of the educational institutions is multifaceted and complex phenomenon of reality six main factors of the intellectual model were appointed in the paper. It is demonstrated that there within the Way of life are internal communications, the basic properties of the laws of development, selfdevelopment and interaction with the environment.
\end{abstract}

Keywords: way of life, educational organization, "hidden curriculum", intellectual capital, cumulative effect

\section{Introduction}

Nowadays rigorous academic standards of secondary school management and their suitability to social, historical, political and economic realities of the development of civilization require the academic evidence different points of view on the problem of educational organization life way. In educational sphere there the scientific, cultural, economic basis of any society is formed. There is a mutually conditioned relationship between the processes taking place in any society and the level of development of educational space. Frequently almost similar in their components educational systems give different, and even opposite results.

The fact is that the conditions created in each educational institution can not but affect the results of educational process. The problem of updating the structure and content of education is directly related to the peculiarities of life of educational establishments and their way of life. However, the current goals of education - to teach a man to study, to endorse globalization trends, to determine own personal direction, to inculcate the new requirements to the results of educational programs, to readjust the object of evaluation to the social and personal competencies, to arrange the programs of continued development of educational institutions - is, unfortunately, more failures than successes. New ideas do not reach the practice because they conflict with deeply rooted educators' ideas about the education.
But it is known that management of organization development is the major internal reserve of improvement of quality and efficiency of system activity and designing - a way to effective revealing of organisation laws, information links, communications and use of this reserve. Social and economic management considers managerial processes in heterogeneous systems from the point of view of unity of various systems' behavior, i.e. operates with laws of interaction information at several levels of the organisation.

According to Japanese theorist of organisation Ikudziro Nonaki, in economy where with definiteness it is possible to tell only about uncertainty, many managers consider a company to be a version of the mechanis $m$ for «information processing» and believe that unique useful management consists of operating by measured data the latent views, sensations and ideals of employees - is the unique true source of reliable competitive advantage.

The need to improve the efficiency of human activity in the management and the sphere of information processing makes it necessary to provide reliability of systems. It can be provided, if duplication of functions of elements of system; possibility of their restoration; creating a kind of "super organism" [1] by efforts of many people; the socalled "collective brain" [2]; optimu m behavior of system under control actions is provided.

Any organization hopes to compete in the market of educational services successfully. Thus everyone understands that it is possible to compete only on the basis of effective cooperation within the company. Leaders of today's organizations are interested in the effective use of 
human capital. Brilliant ideas are born by most of the team in the clash of ideas, ways of processing and interpretation of available information.

As different people perceive the reality in different ways, it is necess ary to clarify important concepts such as compatibility and harmony. Understanding of these differences is particularly important nowadays because the creation of complex modern products is impossible without collaboration of individuals who are known to be poorly understood by one another due to natural features.

But the smart leadership will use the energy released during clash of different styles of thinking and drive innovation. To achieve this, you need to learn different approaches to problem solving, i.e. to use the collective intelligence of the organization.

All over the world the modern school experiences the period of complex reforming. The ideas about the results and the content of education, the organization of the educational process, the nature of the interaction of its different members are changing. System modernization of secondary school is derived from those of socio-economic and cultural changes characterizing a society that is more often called the knowledge society, the post-industrial society. In promptly updating world where borders of an objective and virtual reality are displaced, both possibilities and requirements of the person extend, the main task of the school is - not only to provide fundamental knowledge to the child, but also to give him the experience of independent activity which is formed in the context of responsibility, willingness to choice, to the successful socialization and active personal position.

\section{Examination of the Problem}

When we talk about the development of the educational institution we must take into consideration three the most important areas of wide enough concept of "intellectual capital".

They are:

- Human capital including know-how, qualification, knowledge and experience, skills, loyalty, motivation and ability to work in a command;

- Internal intellectual capital which includes systems, politics, culture, internal learning processes, all kinds of the so-called ability of an organization such as its features, which distinguish it from other educational institutions, increase its value. A very important part of this element of intellectual capital is ability to update and improve the present educational processes;

- External intellectual capital, which consists of the relationships that are formed with respect to the organization, for example, it may be a relationship of students, alumni and partners.

Besides two fundamental concepts of Way of school life - education and culture - are combined by the category of "educational space". Integration into the overall semantic space gives each of them added value. Space, integrated with education, is not equal to the space itself. In the context of education, the space expands to its cultural-anthropological dimension. Education in the context of the space also takes on added significance. It fills the whole human life, society and culture, opens itself in the space of human existence and gets a clearly defined cultural accordance.

Today, when the development of our industrial society has come to critical points that mark the limits of its growth, the man found himself in a situation of uncertainty value. The crisis of rationalis m leads to thoughts about the loss of culture as the basis of human existence. Education worries the situation of "loss of culture" also.

The development of industrial civilization has gradually led to the replacement of "personal culture" by "mass culture." Mass culture and the man of mass was characterized by X. Ortega y Gasset: "mass man" is just like all the others, and the rest - it's a lot of people with no special advantages, average, ordinary people who are not given to design, plan, they always go down stream, they can not create, no matter how great was their ability, their power" [8]. Return of the priority place in the world to the culture, "rescue of culture" is as sociated primarily with the development of education.

There is a need to make the methodological foundation of culture in education, since Culture is the condition of education, and Education is the condition of culture. It is necessary to realize actual requirements of the world community for the person which is focused on cooperation and does not make destructive actions. It means an embodiment of following ideas in educational space:

- Education of the "safe person" which does not cause harm to people, neither the nature nor to himself;

- Education of the "language person" capable to be careful with the words, loving own language and faithfully concerning languages of other people;

- Education of the "State person" capable to accept active participation in complex public, economic and political processes, in administrative activity of various level.

The relationship between education and culture and between education and a student is defined by the principle of cultural accordance. At this principle education "encourages cultural self-development of the person", attaches him to the values of culture and creates the conditions for individual and creative fulfillment. The principle of cultural accordance involving cultural identity, freedom of choice and implementation of the principle of cultural accordant lifestyle behavior, self-determination is the result of relation to culture as to an important educational factor that lays the foundations of emotional and intellectual development of moral values.

The educational space in borders of self-determination of the person is created by the schoolboy together with the teacher, but not by church, by the state, by the teacher himself for the purpose of of cultural values translation. The conception of

Proceeding from the above-stated provisions we represent the basic concept: Way of a school life thanks to the "the hidden curriculum", to combination of obvious (defined, generated, external) and imp lic it (universal, nonformalized) characteristics provides students involvement into the complex of values, traditions, human relations, social and cultural practice. Thus there the conditions are created when the child does not "prepare" for a life but lives, solves tasks significant both for himself and for other persons, updates knowledge received and abilities formed, gets necessary practical experience. 
The intellectual model of Way of life of educational institution - is a model of such a space where the students can demonstrate:

- Ability to study and the ability to self-organizing of their activit ies (planning, monitoring and evaluation);

- Ability to accept, design the purposes and to follow them in educational activity;

- Ability to operate under the plan and to plan the activity;

- Ability to supervise process and results of the activity, including anticipatory control;

- Ability to perceive estimations adequately;

- Ability to distinguish objective difficulty and subjective comple xity of a problem;

- Ability to co-operate with others in education;

- Aspiration to purposes and persistence in achieving goals, a willingness to overcoming, installation on finding ways to resolve difficulties, an optimistic view of the world.

The history of education shows that, as educational institutions coped with internal and external difficulties, each of them formed a specific set of accepted models of behavior, artifacts, values, beliefs and concepts - the Way of life.

Educational space is not an isolated phenomenon in modern education, but the education itself, becoming a phenomenon of life. Modern education oversteps the bounds outlined by traditional culture, and gains the status of the dominant socio-cultural system. Education incorporates culture and pervades the society [3].

This is possible due to the fact that culture and society are modified as well by extending their boundaries to the limits of nature, mastered by man in this or that way. Culture, society and nature are integrated into a holistic, complex structural space of human existence, bound together by multiple and continuous processes of human education.

That is why the relationship between intellectual models (IM) and the perception is particularly important in the management of educational institutions. All models are by definition the result of simplification. The problem in education is that smart models exist implicitly and grow into strong tradition of educational institution. What can fully enforce the requirements of modern consumers of educational services and the full implementation of modern management principles in the operation of educational institutions? Despite the fact that most of the mental models preserve outdated management practice sprouts of new thought occur in educational practice.

At the beginning of XXI century, education was enriched by a fairly new concept for his story "The way of life of the educational institution."

The way of life - is a generalized characteristic of the educational institution at any level and type, reflecting the relatively stable and regularly features most relevant to the content and quality of life of all persons working and studying (its subjects). Understanding of this characteristic meets difficulties related to its name from the middle of $\mathrm{XX}^{\text {th }}$ century.

The American scientists have presented its designation through substantial content. Sociologist Philip Jackson who considered the content of education to be more than the total number of units of the content of the curriculum used the term "hidden curriculum" [4]. N. Overlay also drew attention to the fact that in schools there is a certain phenomenon, which he called "non-being-taught curriculum" [5]. Roland Meighan believed that so-called "hidden curriculum" is represented not by the teacher at lecture and not even at any meeting but with whole educational institution that offers a choice of attitude to education and approaches to life [6]. Ya. Miller, U. Sellev, $X$. Daniels considered that phenomenon to be very important and named it later - "the institutional context of education". In their work, this term is understood as peculiarities of co-organization of various processes, including specific communication between the teachers and students [7].

A special phenomenon has appeared at the end of XX beginning of XXI century in the innovative educational practice in Russia. It can be defined as "the way of life of an educational institution" and determines the educational effect not less than programs worked out by highly qualified teachers.

In modern conditions, necessity of formation of the intellectual capital for educational institutions is highlighted with State standards of education.

Indeed, any changes in education are not only unsuccessful, but also meaningless if they do not find support in the spiritual life of the individual, if they are not supported by adequate changes in the people's values. The development of the individualities without the formation of intellectual lifestyle of educational institution leads to the fact that people do not develop as an active creative person capable to overcome the contradictions of personal growth and reach a new level of development, as the creator of himself, but turns into user of the social opportunities offered by educational system.

\section{Modelling}

Predictive modeling is perhaps the only scientific method by which the problem of system investigation of educational space can be solved a little well. The first difficulty we face in attempts to reveal the framework of the problem - its exceptionally large substantial amount. The fact that the term "educational space" was introduced in the scientific use very recently, should not obscure the deep scientific, cultural and educational traditions on which it is based. Category of "educational space" is the scientific product of a special kind. We should not think that it arises as a special form of a new understanding of the phenomena of educational experience along with many others.

The way of life of educational institution understood as the environment for the statement of self-value of the human person, of respect to his rights, dignity and freedom, education and training, is exclusively actual in conditions of globalization. Innovative environment of lifestyle of educational organization determines strategic intellectual position in which there are teachers and students. Such position is determined with the new mental potential of organization and a new intellectual climate - the status of the organizational macro-and microenvironment ( 1).

Very important educational effect of Lifestyle is a harmonization of educational training, socially useful, work and aesthetic, social, communicative, creative, and 
other activities of the students. And one more effect is that teachers have the possibility to select teaching methods, to use various forms of educational activities.

This is a non-material analyzer, providing information to a person on various aspects of the system, giving it a value, direction and the basis of its life. It defines the organizational space in the environment, represents those unwritten laws, rules and regulations that bind people in organization and link them together (Figure 2).

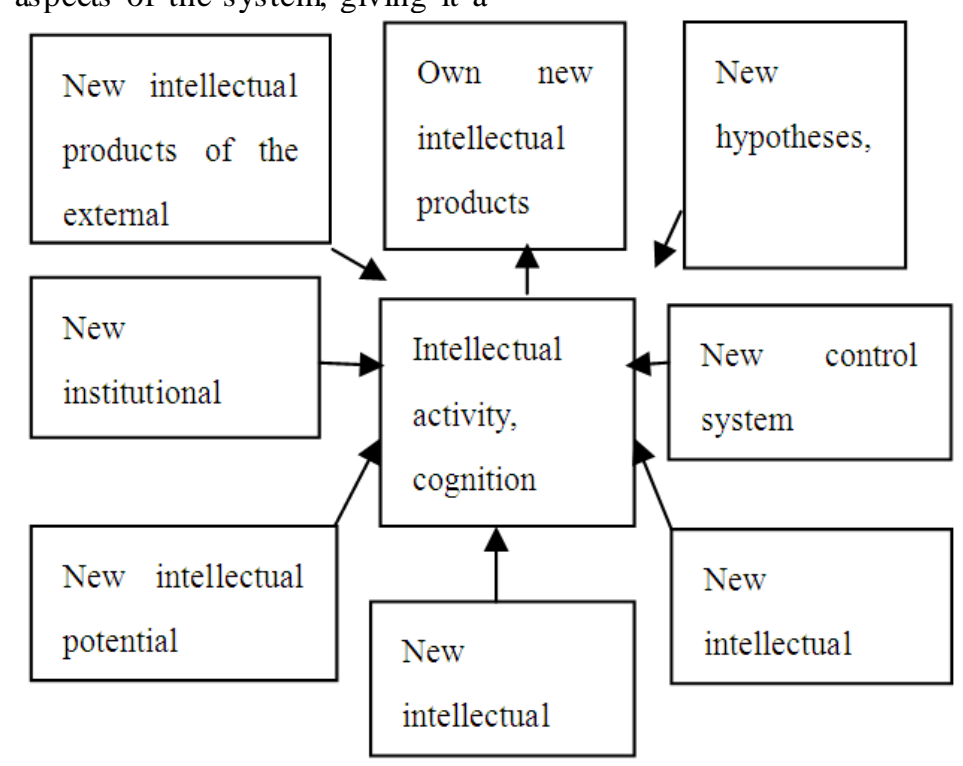

Figure 1. Intellectual climate of the educational organisation

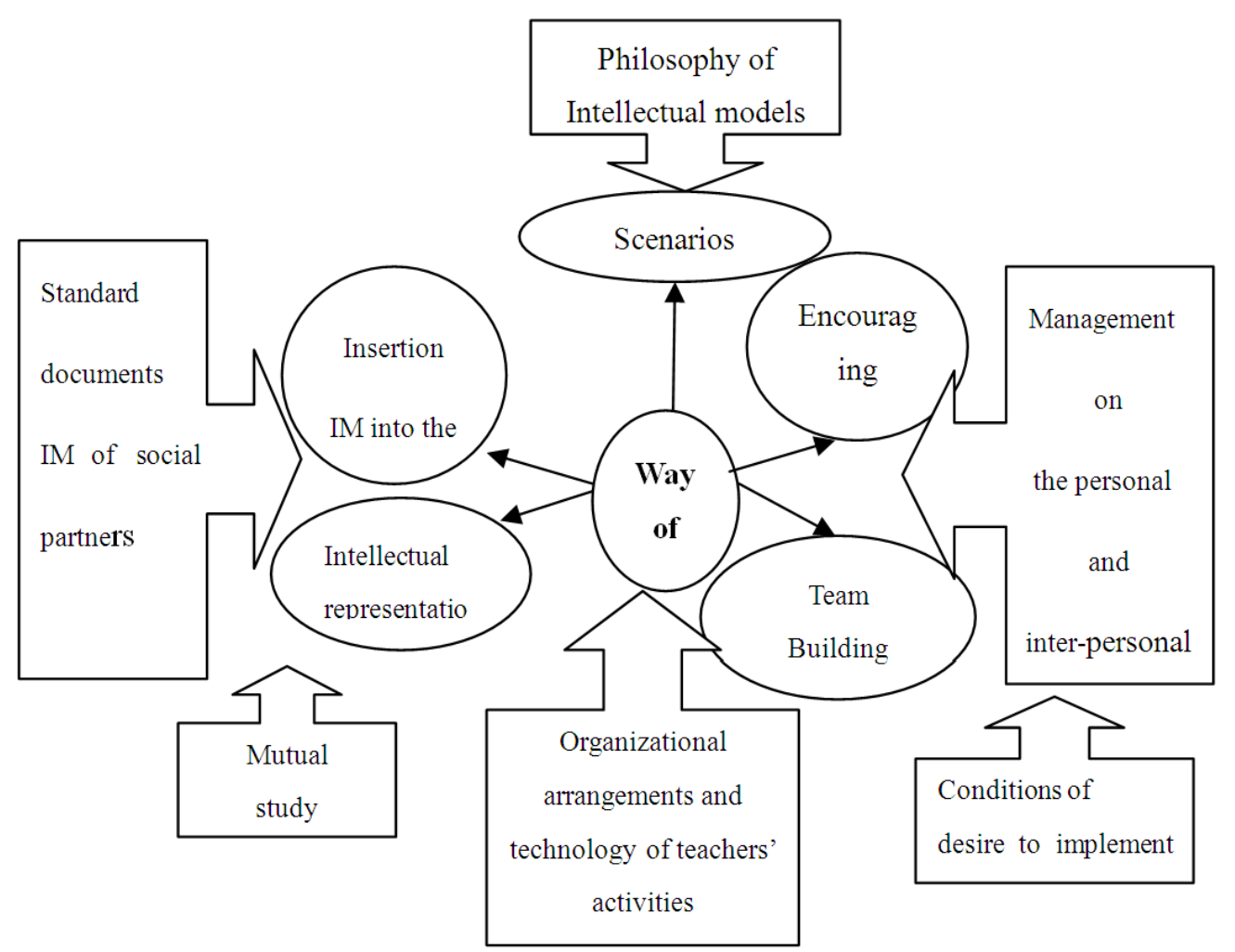

Figure 2. Intellectual model of an educational institution's lifestyle

To institutionalize the process of identifying and understanding mental models one needs mechanisms that will make the practice inevitable:

- Philosophy of generating mental models is required;

- Management of intellectual models begins with scenarios;
- Insertion Intellectual Model into the processes of planning;

- Discussion of the questions connected with internal activity promotes ability to understand other points of view and to be persistent, persuasive and open at the same time; 
- Management of mental models on the personal and interpersonal level;

- Presenting your ideas to public scrutiny - "Mutual Research";

- Conditions for the implementation of the desire to change.

Way of life of the organization by its nature is more inert than the rest of the management system as well as intellectual models of people do not have time to adapt to the very rapid changes in the material sphere. One of the most effective ways to change lifestyle representations in educational institutions in line with the changes of maintenance of education is to find a model of intellectual way of life mastering new personal skills, the introduction of organizational changes so that these skills were put into practice.

Main principle of management of an educational institution is conformity of Way of its life to all ele ments of a management system.

In practice this principle means, that by working out or introduction of changes in strategy, structure and in other elements of a management system caused by new circumstances it is necessary to estimate degree of their reliability within the limits of existing organizational Way of life and if necessary to develop the program on its change.

Based on this principle we can offer the use of a hidden cumulative intellectual model, which can be manifested in two aspects. In the first - there is a gradual evolutionary expansion of the intellectual capital of the organisation when the new points of view supersede many positions and the rituals which are an integral part of the old regime. In the second - «intellectual technologies» are coming to replace the so-called "technical technologies" and open a wide range of tasks.

Such technologies that are not reduced exclusively to scientific and technical problems act in the form of well thought over decision for the purpose of attraction of members of the organisation to new type of behavior that demands from the m revaluation of existing representations and, probably, acceptances of new values, beliefs and representations.

The intellectual model of Way of life of the educational organization is defined by six factors [9]:

- Precision of understanding (comprehension, interpretation) of the problems of activity;

- Knowledge of that responsibility for quality of educational process rests entirely on persons of concrete Way of life;

- Integral part of Way of life should be continuous innovation. It must be included in the educational process. Factor is how much each person has the innovation activity in the right place;

- An employee of the educational institution should be in a mode of continuous and pervasive learning process. On the one hand he must constantly study himself and on the other - constantly teach others;

- Measurement of productivity of the educational organisation employee is mainly carried out through an estimation of quality of his performance. The productivity is not measured only by quantity or the amount - anyway, it is not the most important indicator;

- How much they look at the employee in the organisation as at "capital" and how much it meets the conditions established in the organisation for its development.

The way of life of the educational institutions is so multifaceted and complex phenomenon of reality, that the best way of its studying is to build the intellectual model displaying at least some sides of a reality but consequently is much more simple than a reality itself.

\section{Conclusions}

The proposed theoretical model of Way of a life of educational organization represents the basic semanticsymbolic system, compiled on the basis of experience of the theoretical modeling of complex objects of education, the results of modeling space in other sciences, analys is of various models, the reduction of their elements to a holistic way of educational space.

In constructing such a model, the researcher always takes into account only the most significant factors. We start with the idea that the emergence and development of the modern Way of life of an educational institution is directly dependent on the characteristics of the educational process, where the mode of open interaction with different persons is built.

Of course, the selection of certain factors makes any model no identical to the object and, therefore, incomplete. Our model reflects only some of the key features of the original object but the account of then however is particularly important in the study of lifestyle of educational organization. It shows what's there inside the Way of life: internal communications, the basic properties of the laws of development, self-development and interaction with the environment. But this is the only one of the characteristics of the proposed model.

Its potentiality can be considered another important characteristic. That is, the potential knowledge that is contained in this theoretical model can be used in building a practical Way of life of educational organizations:

- identification and justifying all possible target functions of lifestyle in the first few successive stages of its development;

- formulation of hypotheses to achieve the objective function for each stage;

- determination the structure of school life, etc.

The theoretical model explains how to manage the object: to include or exclude certain communications, change their orientation, to understand the importance of the way of the behavior of the system as a whole. Since education is a moving entity a particularly important aspect is the ability to predict the shapes of lifestyle under the influence of various factors provided by the model.

As acknowledgement of this thought can be found in the experiment on introduction of the idea of intellectual model in some secondary schools spent by the author. Results of the schools participating in experiment are:

- Winners of national competition among the schools which are carry ing out innovative activity $(2006,2007)$;

- Assignment of higher status "lyceum" during accreditation (2008);

- Assignment of the status of an innovative platform «Formation of way of a school life as bases for development of the maintenance and technologies of education» (2010); etc. 
The theoretical model of Way of life - is not just one of the means of displaying the phenomena and processes of modern education. Despite defined relativity, it is a practical criterion for checking the validity of our knowledge. The application of this model in the organic unity with other methods of getting knowledge will help to establish a process of deepening the knowledge, of its movement from a relatively poor information model to a more meaningful, more complete way of revealing the essence of life of educational organization.

\section{References}

[1] Popov V. N. Systems analysis in management. Moscow, KNORUS, 2007. -304
[2] Leonard, D., Straus C. Knowledge management. Series "Classics Harvard Business Review» - Moscow, Harvard Business Review, 2006. -208

[3] Korsakova T.V. Way of the school life: obvious result of the hidden curriculum. LAP LAMBERT Academic PublishingGmbH\&Co.KG. Saat brucken, 2011.

[4] Jackson, P. Life in classrooms. New York: Holt, Rinehart, and Winston. 1968

[5] Washbourn K. New schools of Western Europe. Moscow. Posrednik. 1982.

[6] Meighan, Roland. Sociology of Education. New York: Holt, Rinehart and Winston, 1981.

[7] Tubelsky A. Thoughts about school way. The First of September, № 23. 1999 Г.

[8] Ortega-Gasset H. Revolt of the masses. Moscow. ACT, 2003.-389

[9] Drucker P. Task of the manager in the XXI century. Moscow, Publishing house "Williams", 2000. 